\title{
Investigation in Human Health, Environment and Safety Aspects of Additive Manufacturing (AM) Processes
}

\author{
Hamidreza Javidrad \\ Department of Mechanical Engineering \\ Iran University of Science and Technology \\ Tehran,Iran
}

\author{
Mostafa Larky \\ Department of Mechanical Engineering \\ Iran University of Science and Technology \\ Tehran,Iran
}

\begin{abstract}
Environmental impacts of every manufacturing procedure are a major consideration in every industry. These impacts include human health and safety and environmental burdens which are known as vital concerns in the industrial world. Before accepting any new process as a part of manufacturing procedure, a clear landscape from every aspect of that process should be provided. Additive manufacturing (AM) is growing from a prototyping method to the level of manufacturing functional products which require specific and accurate characterization information about every step of the whole production line. In this paper, attempts are made to address environmental impacts and safety considerations of metallic AM-based processes as well as their applicable solutions. AM processes are compared to conventional manufacturing methods from environmental aspects. Moreover, the benefits of metal AM as a fabricating and repairing method are presented. In conclusion, AM potential as a substitution or even complement for conventional manufacturing methods are discussed, where safety is considered vital.
\end{abstract}

Keywords: Additive manufacturing (AM), hybrid manufacturing, life cycle inventory (LCI), human safety, environmental impacts.

\section{INTRODUCTION}

Every manufacturing activity has specific impact on the environment and manufacturers have attempted to lower their environmental burdens. Conventional manufacturing methods, including all types of subtractive manufacturing methods cause a lot of material and energy waste. According to International Energy Agency (IEA) [1], the electricity usage of industries are about $42 \%$ of the world electricity consumption which means any applicable method to reduce the energy consumption would be highly considered.

Additive manufacturing (AM) is defined as the process of joining materials to make objects from 3D model data, usually layer by layer, as opposed to subtractive manufacturing methodologies [2]. Metal additive manufacturing processes such as selective laser melting (SLM), electron beam melting (EBM), direct metal deposition (DMD), etc., have been accepted by many major industries such as aerospace and automotive. AM-based processes present more efficient mean to fabricate parts in low production volume such as prototypes, tools and complex parts. Also AM enable the ability to fabricate lighter parts with the same mechanical properties. This approach could also improve human safety. Another use for AM-based processes could be the utilization of AM in repairing and remanufacturing applications. This approach could reduce the volume of material and energy used for manufacturing.

In this paper, attempts are made to assess a number of AMbased processes advantages, potentials and environmental efficiencies in comparison with conventional manufacturing processes through several case studies. Furthermore, utilization of $\mathrm{AM}$ as a fabricating and repairing process is discussed in detail. Environmental impacts of AM are identified and some solutions and guides are proposed in order to make AM processes more efficient and green.

\section{AM ENVIRONMENTAL EFFECTS}

Manufacturing processes have major impact on environment and human health; therefore, they should be environmentally characterized and identified the effects. Three main manufacturing processing types are (1) Bulk-forming, (2) subtractive manufacturing and (3) additive manufacturing. In bulk-forming usually a die or mold is required. Bulk-forming is an economical way to fabricate parts with high volume rate. Subtractive processes such as all types of machining processes are building parts from a material block. These types of processes are used for medium volume rate of production of parts with medium complexity. In contrast, additive manufacturing processes build parts near-net-shape from powder or wire. AM-based processes are mostly used for complex and low volume rate of production such as tools. The main process of each method is shown in figure 1 . Thanks to the new production methods, decision making for the most efficient fabrication method gets much harder. Therefore, the environmental impacts of each production method such as energy consumption of every step of manufacturing including material and equipment preparation should be taken into consideration to obtain accurate understanding about process costs. Such model is called life cycle inventory (LCI). This helps manufacturers to decide which procedure is more efficient for their production purpose. To this end, a wide LCI database for every material and process is required. Collected database would be developed as a built-in software for every AM machine in order to pick the best manufacturing strategy. 


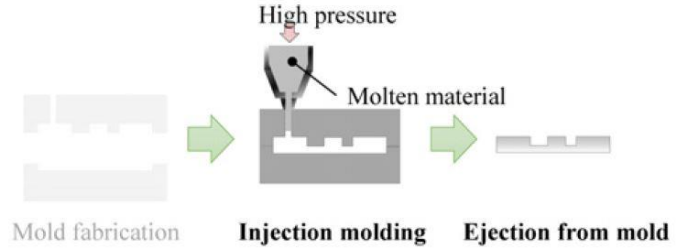

(a) Conventional bulk forming process

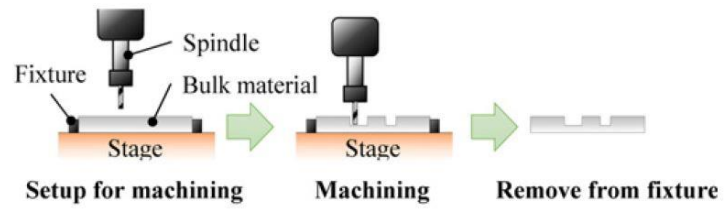

(b) Subtractive process

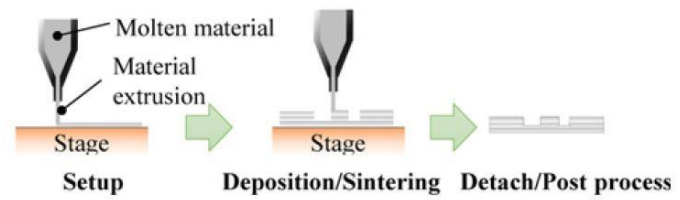

(c) Additive process

Figure. 1 Schematic diagram of the three manufacturing processes considered in this study; only the main processes were considered [3].

Several studies are dedicated to compare conventional manufacturing with AM-based manufacturing methods from environmental aspects [3, 4]. As a conclusion, fabricating parts with complex geometry which take excessive time or different processes to build and parts in low volume of production are economically and environmentally feasible to be done by AM processes. Moreover, it is forecasted that air transport will increase by $45 \%$ from 2014 to 2035 [5]. Consequently, the use of lightweight parts could cover some of the greenhouse gases produced by aircraft. One study is revealed that if weight reduction is higher than $50 \%$ and the part is used in aircraft, AM processes would be preferable [6]. The number of parts required for a module could be reduced with AM products as well as weight reduction. AM provide the ability of designing according to functionality over possibility. For example, the new fuel nozzle of jet engine made by Airbus is $50 \%$ lighter and also more efficient. It is made via AM as a single part except 20 parts in prior versions. Another study investigates efficiency of LBM process in gear fabrication and finds it energy efficient for low volume production [7].

A typical AM process procedure is shown in figure 2 . Environmental effects are considered as determinant key factors in the way of part fabrication. Every step of AM processes has its own environmental impact. For example, powder production is done by several methods which mainly depend on material type and the required particle size. Also the scenario chosen for powder production is one of the most energy consuming parts of the LCI. Lutter-Guenther et al. [7] suggested choosing an efficient procedure to atomize powder for LBM process.

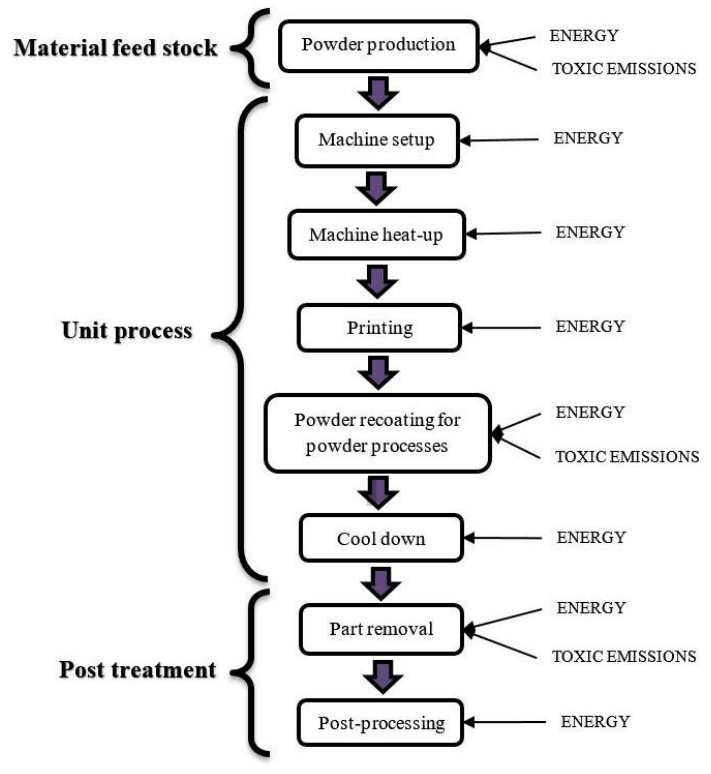

Figure. 2 A typical AM process procedure [8].

Environmental effects could be investigated from several aspects: (1) energy usage, (2) material and fluids (e.g. protective gases) usage, (3) human health and (4) harmful emissions. Every aspect should be taken into consideration in order to accurately model each one. The only way to assess these key factors is to compare them with conventional part manufacturing methods such as machining and forming. There are few studies that investigated metallic AM processes such as SLM from environmental aspects. A recent study is dedicated to compare SLM process with machining and forming process through a part fabrication case study from environmental aspects [6]. This study reveals that if weight reduction is higher than $50 \%$, additive manufacturing approach seems to be environmentally superior. This substitution is much highlighted when the part is used in transportation systems especially in aircraft. Another study by Kafara et al. [9] showed that AM-based processes have the lowest environmental impact among other candidate processes in CFRP mold core fabrication.

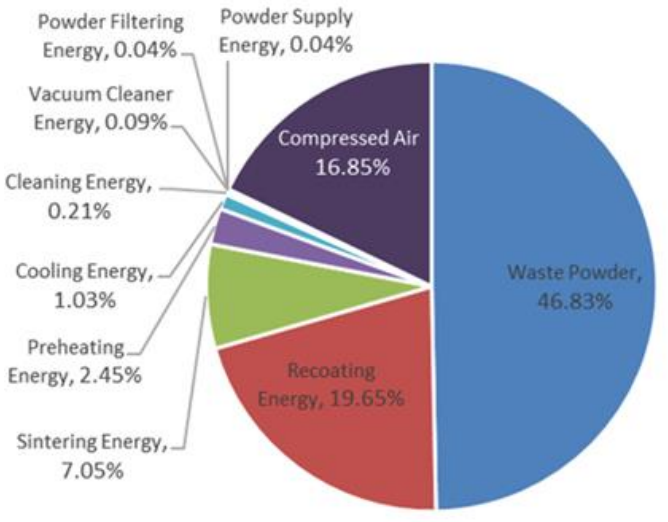

Figure. 3 Environmental impact distribution of 1 hour of SLS of PA2200 with a layer thickness of $120 \mu \mathrm{m}$ [10].

Environmental effects of AM processes are highly related to selected process, process parameters and process equipment 
such as laser, building chamber volume, etc. [11]. For example, environmental impact distribution of one hour part fabrication with PA2200 setup through selective laser sintering (SLS) method with a layer thickness of $120 \mu \mathrm{m}$ showed that up to $50 \%$ of power is wasted (see figure 3) [10]. Such model is required for other metal AM processes like SLM, DMD, etc.

As mentioned above, an accurate model is required to evaluate consuming energy and material for fabrication to decide whether AM is environmentally and economically beneficial or not [12]. It is also important to provide clear documented information about environmental effects of AM feedstock production [10]. Besides, AM processes could be used for in-house fabrication or spare parts fabrication which is effectively reduced the environmental effects by eliminating unnecessary transports [13]. As shown in figure 4 every step in conventional production methods require a transport step which is avoidable by AM methods.

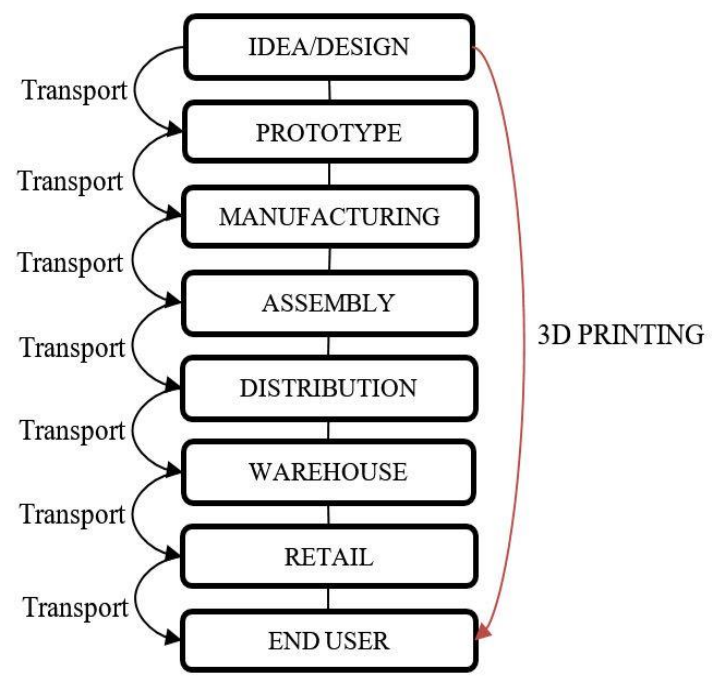

Figure. 4 Traditional versus 3D printing supply chain [13].

There are several studies developed predictive models for AM-based processes to evaluate the amount of energy and material consumed during the fabrication procedure. Kellens et al. [10] assess available LCI data and compare them for SLM and other processes as well as the impacts during material production and post-processing. Post-treatments such as detachment of part from the building plate is a part of process that neglected or underestimated during the environmental assessments most of the time. Faludi et al. [14] showed removing parts by electron discharge machining (EDM) will add more energy consumption than conventional processes. They also determined that the use of SLM machine for a single part production would not be an excellent choice. However, using of whole building plate will significantly reduce the building energy consumption. Bourhis et al. [15] developed such model for DMD process as well as powder atomization process to assess energy, fluid and material consumption used for part fabrication. A predictive model for each factor's consumption is proposed.

\subsection{Electrical Consumption}

Electric use of machine is divided into two main categories: (1) constant energy consumption referred to hydraulics components and electrical cabinet, (2) referred to electrical consumption due to part geometry and machine setup. The model proposed by bourhis et al. [15] is:

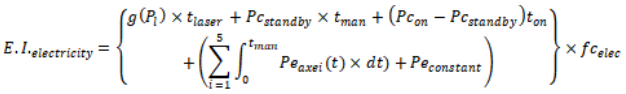

\subsection{Material Consumption}

Material use during the process is highly depended on nozzle efficiency. An analytical model for this factor is developed by previous authors [15]:

$E_{.} I_{\text {material }}=\left[e_{n}+k \times\left(1-e_{n}\right)\right] \times d_{p} \times t_{\text {man }} \times f c_{\text {material }}$

Powder recycling could significantly reduce this load, however, unfused powder require treatments such as drying and sieving before reuse due to possible damages to the machine [15]. This require deeper study and experiments to find out if the recycled powder have the same characteristics of brand new powder. One study investigated in properties of Inconel 718 parts which built with recycled powder by means of SLM process [16]. The metallographic and mechanical properties of Inconel 718 remain the same as brand new powder, however, further studies are needed to confirm other mechanical properties such as fatigue.

\subsection{Fluids Consumption}

As mentioned previously, fluids include inert gases that add to building atmosphere to protect melting pool from oxides. Inert gas which mainly use in AM processes is argon due to its safety and price. Environmental impact of gases assess by the Eco-Indicator 99 (fc) which multiply to the proposed model below [15].

E. $I_{\text {ffluids }}=\left[d_{c}+d_{f}\right] \times t_{\operatorname{man}} \times f c_{\text {argon }}$

As indicated above, the highest environmental impact in utilization of $\mathrm{AM}$ is the energy consumption during the process. One solution is the combination of AM-based processes with conventional processes to obtain more efficient way to fabricate parts. A study by Paris et al. [17] developed an innovative strategy based on combination of EBM and CNC milling to reduce environmental impacts which is mainly considered as electricity consumption. In their work, existing parts are recycled to build new parts. It is believed that such combinations could be more environmentally friendly. Such combinations are known as "hybrid process". Kaplan and Samarjy [18] employed a laser-driven drop jet to build parts from waste metallic materials such as scrap plates. This procedure seems to be feasible to recycle old parts but environmental aspects of this procedure are not identified yet. Another solution could be the combination of DMD process with $\mathrm{CNC}$ machining or casting process. For example, simple sections of a part could fabricate through CNC machining, casting or even forging and after that DMD process would be employed to take care of complex sections of the previous part. This method has similarities to the welding process with computer-aided three-dimensional building capabilities. Therefore, this method benefits both conventional and modern manufacturing processes as the simple sections of the part which are time-consuming to fabricate by AM-based processes could be done by conventional methods and fabricating of the complex sections which is known as limitation of conventional methods done by AM processes. This innovative method has an obstacle which is the distortion of base material caused by the heat added to the part during DMD process [19]. This problem is not fully investigated; 
however, one solution proposed by [19] is to use machining after metal deposition in order to obtain more geometrical accuracy. Another solution may be hot isostatic pressing (HIP). In some cases, this approach prevents post-treatment by avoiding part removal stage. Besides, building plate should be replaced after specific number of building cycles because of detachment damages which is added extra cost. Figure 5 shows an example of this innovative method for turbine blade fabrication. In such cases, ceramics with high life cycle could be replaced with metallic building plates.

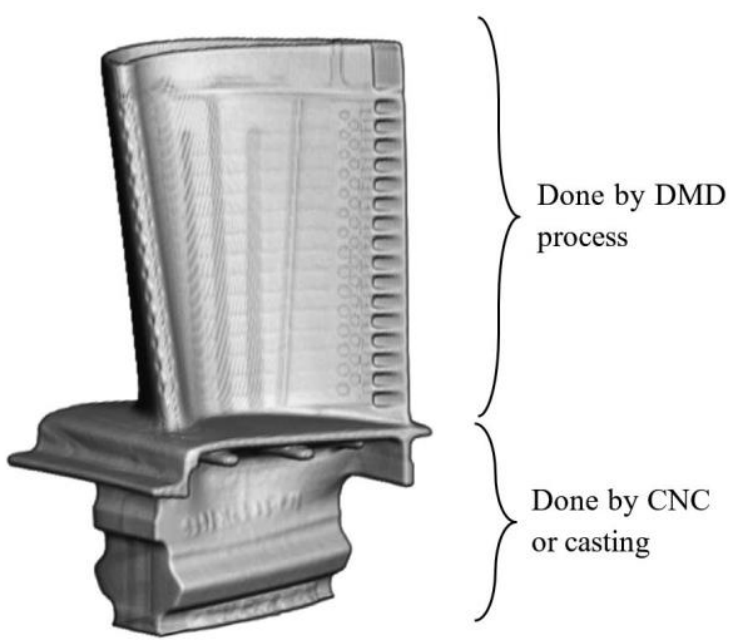

Figure. 5 An innovative combination of AM and conventional manufacturing processes to achieve more efficiency.

\section{AM AS A REPAIRING METHOD}

Metal AM-based processes could be used as a repairing tool for both parts and tools repair. This revolutionary solution provides longer lifespan for mechanical parts which lead to a lot of energy and material saving as shown in figure 6 . Applicable strategies should be developed in every industry with respect to their criteria to employ optimum procedure for repair and remanufacturing purpose.

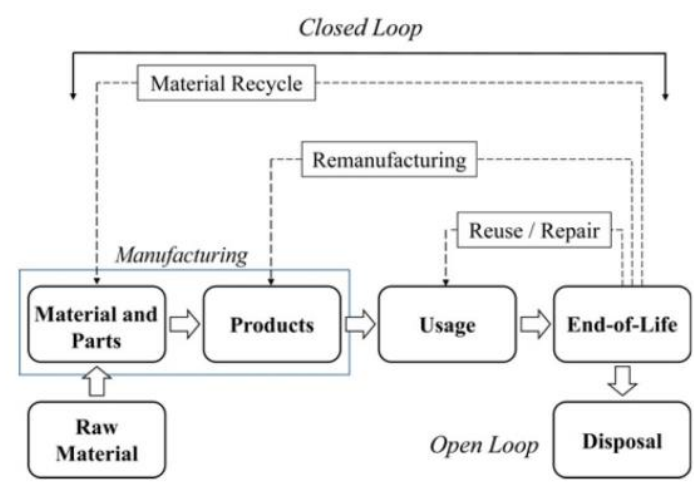

Figure. 6 Conceptual diagram of resource circulation [20].

Another positive point about repairing parts in order to back them to their life cycle is the reduction of transferring key parts such as tools [21]. This approach could also be seen in spare parts production [22]. Spare parts usually are stored far from the workshop where they are needed which means it takes a lot of time to transfer. With the aid of in-house keypart production, the production lead time could be avoided
[23]. Repairing procedures are mainly used for key-parts like tools but it could be used for scrap parts as well. This approach eliminates material and energy waste. There are several studies investigated possibilities of tooling by means of metal AM [24, 25]. AM have several exclusive features that make it even more efficient than conventional tooling processes. These features including conformal cooling channels (CCC) in order to enhance cooling rate, porous structures for lighter products, complex geometries such as custom molds, etc., not only increase production rate but also decrease the environmental impacts and costs. Part repairing and coating increase product lifespan which improves safety in some cases. Figure 7 show overall benefits of repairing by means of AM processes.

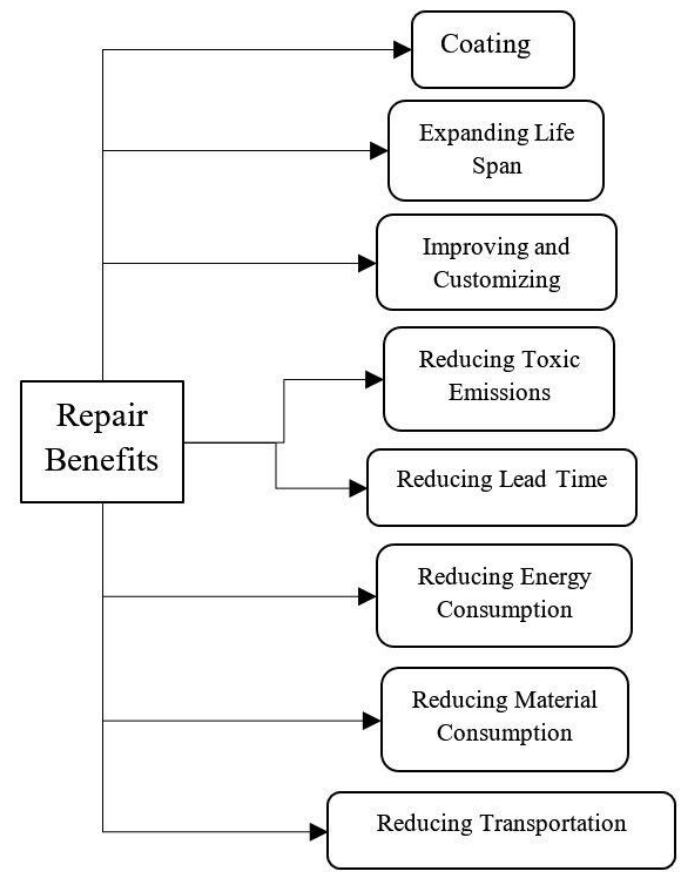

Figure. 7 Overall benefits of repairing by means of AM processes.

\section{HUMAN HEALTH AND SAFETY}

Human health safety and exposing to process emissions are also very important during the building phase. However, there is no referable information about human-related harms for metal AM methods yet. Metal AM processes are kind of welding processes; therefore, the danger of emitted toxic heavy metal vapor require consideration. Besides, floating metal powder particles could cause respiratory problems in both powder production and AM procedure. Therefore, every step of manufacturing including powder transport, powder storage, powder recycle, etc., should be carefully considered. Existing standards have not addressed all the safety concerns and it is mainly up to operators and manufacturing conditions (e.g. product rate, workshop conditions, ventilation, etc.) [26]. Feedstock should be supplied from reliable sources with specified composition to avoid toxic emissions as much as possible. This issue may be related to process parameters; however, further studies are required to understand the relationship between feedstock/process parameters and emissions. Besides that, optimum process parameters would lead to perfect product which eliminate post-processing and scrap parts. Another consideration is exhaust gases that should be managed very carefully as well as floating nanoparticles. 
Metal AM processes are mainly done by laser power or electron beam which bring the risk of danger for human eyes [27]. Process safety management could be achieve through the use of data collecting methods such as cyber-physical systems and Internet of Things by avoiding hazards and accidents by identifying and controlling potential sources of failure [28].

From another point of view, safety may be considered as human life. This approach could be widely found in aerospace industry which deals with human life. The European Aviation Safety Agency (EASA) is responsible for certifying civil aircraft parts. They have begun to evaluate AM products for flying and critical parts, yet AM products had been used in cabin equipment. However, safety standards of AM products are still under development for critical use [29]. From the safety aspect, repaired parts which would be used in safetycritical industries such as aerospace should be tested and verified by professionals. In case of spare parts, in-situ inspection systems should be employed to evaluate part quality and integrity to avoid unpredictable failure. Moreover, nondestructive evaluation techniques play a crucial role in certifying key-parts. However, destructive tests such as tensile and fatigue tests are suited for determining material properties and behavior in different situations. To achieve higher mechanical properties, post-processing treatments such as hot isostatic pressing (HIP) are required [30].

In case of human implants, there are three class parts which could be fabricated by means of additive manufacturing processes. Class I is associated with low-risk parts such as dental implants and class II is related to higher risk parts with more safety concern and functionality (e.g. woven polylactic acid scaffolds), while class III products responsible for parts like artificial heart valves with the highest level of safety consideration. Therefore, for class III products premarket approval from FDA is required [31].

\section{RESULTS AND DISCUSSION}

With respect to all the studies done to address several aspects of environmental impacts and safety aspects of AM-based processes, still there are many questions about the accurate environmental impacts of additively manufactured part production as well as safety considerations. This problem is mainly because of the wide range of parameters and their effects on process sustainability. However, it seems feasible to reduce environmental impacts of AM by using more efficient laser source, adjusting optimum process parameters and machine setup, reduce weight as much as possible, filtering toxic gases, reducing energy waste by using it for heating purposes such as powder pre-heating or other usages or combination of AM with conventional manufacturing processes. It is found out that powder production play an important role in total manufacturing energy consumption and still have unknown environmental impacts.

Some models are developed recently; however, further studies are required to fully identify all aspects of powder production environmental impacts. AM minimize transport by centralizing production line and reduce unnecessary costs and environmental burden. Moreover, the utilization of AM products in industries such as aerospace which related to human life safety is a major concern and require more investigation.
AM enable several features that make products much lighter and functionally more efficient such as conformal cooling channels (CCC) in molds and casting equipment and porous structures for higher strength-to-weight property. Hybrid processes take the benefits of both AM and conventional processes to fabricate more efficient parts. Repair strategies by means of AM seem feasible and environmentally friendly; however, further studies are required to observe this capability in action. Spare parts and tools could be built by the aid of AM to reduce lead time and following costs.

\section{CONCLUSION}

Metal additive manufacturing is highly promising method for fabricating and repairing parts with lower environmental burden than conventional methods. Hybrid processes make AM even more beneficial, especially for complex parts. Powder related issues including production, usage and recycling require more attention. Energy consumption of part detachment from building plate is a post-treatment which is neglected in many studies should be considered as well as other production steps. More efficient equipment (e.g. laser, electron beam, smaller building room, etc.) should be used. Safety considerations and risk factors should investigate in detail and documented instructions should be developed to avoid injuries. All these risk factors are undefined at this time and require more assessment.

In this paper, Environmental and safety aspects of AM processes are presented. Several benefits of repairing parts and spare part fabrication by means of AM, especially environmental benefits are addressed. Further studies are needed for all types of metal AM processes and powder production methods to fully characterize environmental impacts of each process. Accurate LCI models should be developed for other AM methods.

\section{REFERENCES}

[1] International Energy Agency I. Key World Energy. 2017.

[2] ASTM International, F2792-12a. 2013. Standard Terminology for Additive Manufacturing Technologies. Rapid Manuf. Assoc., 10 - 12.

[3] Yoon, H. -S., Lee, J. -Y., Kim, H. -S., Kim, M. -S., Kim, E. -S., Shin, Y. -J., Chu, W. -S., and Ahn, S. -H. 2014 A Comparison of Energy Consumption in Bulk Forming, Subtractive, and Additive Processes: Review and Case Study, Int. J. of Precision Eng. and Manuf. Green Tech 1, $261-279$.

[4] Faludi, J., Bayley, C., Bhogal, S., and Iribarne, M. 2015. Comparing Environmental Impacts of Additive Manufacturing vs. Traditional Machining via Life-Cycle Assessment. Rap. Protot. J. 21, 14 - 33.

[5] European Aviation Safety Agency EASA, European Aviation Environmental Report 2016.

[6] Ingarao, G., Priarone, P. C., Deng, Y., and Paraskevas, D. 2018. Environmental modelling of aluminum based components manufacturing routes: Additive manufacturing versus machining versus forming. J. of Cleaner Production 176, 261 - 275. 
[7] Kampsa, T., Lutter-Guenther, M., Seidel, C., Gutowski, T., and Reinhart, G. 2018. Cost- and energy-efficient manufacture of gears by laser beam melting, CIRP J. of Manuf. Sci. and Tech. A.

[8] Gutowski, T., Jiang, S., Cooper, D., Corman, G., Hausman, M., Manson, J. -A., Schudeleit, T., Wegener, K., Sabelle, M., Ramos-Grez, J., and Sekulic, D. P. 2017. Note on the Rate and Energy Efficiency Limits for Additive Manufacturing, J. of Industrial Ecology.

[9] Kafara, M., Süchting, M., Kemnitzer, J., Westermann, H.-H., and Steinhilper, R. 2017. Comparative Life Cycle Assessment of Conventional and Additive Manufacturing in Mold Core Making for CFRP Production. Procedia Manufacturing 8, 223 - 230.

[10] Kellens, K., Mertens, R., Paraskevas, D., Dewulf, W., and Duflou, J. R., 2017. Environmental Impact of Additive Manufacturing Processes: Does AM contribute to a more sustainable way of part manufacturing?. Procedia CIRP 61, 582 - 587.

[11] Kellens, K., Baumers, M., Gutowski, T. G., Flanagan, W., Lifset, R., and Duflou, J. R. 2017. Environmental dimensions of additive manufacturing mapping application domains and their environmental implications. J. of Industrial Ecology 21, $49-68$.

[12] Yosofi, M., Kerbrat, O., and Mognol, P. 2018. Energy and material flow modelling of additive manufacturing processes. J. of Virtual and Physical Prototyping, 1 - 14.

[13] Özceylan, E., Çetinkaya, C., Demirel N., and Sabırlığlu, O. 2018. Impacts of Additive Manufacturing on Supply Chain Flow: A Simulation Approach in Healthcare Industry. Logistics.

[14] Faludi, J., Baumers, M., Maskery, I., and Hague, R. 2016. Environmental Impacts of Selective Laser Melting: Do Printer, Powder, Or Power Dominate? J. of Industrial Ecology, $144-156$.

[15] Bourhis, F. L., Kerbrat, O., Dembinski, L., Hascoet, J. Y., and Mognol, P. 2014. Predictive model for environmental assessment in additive manufacturing process. Procedia CIRP 15, $26-31$.

[16] Ardila, L. C., Garciandia, F., González-Díaz, J. B., Álvarez, P., Echeverria, A., Petite, M. M., Deffley, R., and Ochoa, J. 2014. Effect of IN718 recycled powder reuse on properties of parts manufactured by means of Selective Laser Melting. Physics Procedia 56, $99-107$.

[17] Le, V. T., Paris, H., and Mandil, G. 2017. Environmental impact assessment of an innovative strategy based on an additive and subtractive manufacturing combination. J. of Cleaner Production 164, 508 - 523.

[18] Kaplan, A. F. H., and Samarjy, R. S. M. 2017. CYCLAM - Recycling by a Laser-driven drop jet from waste that feeds AM. Physics Procedia 89, 187 - 196.

[19] Zhu, Z., Dhokia, V., Nassehi, A., and Newman, S. T. 2016. Investigation of part distortions as a result of hybrid manufacturing. Robotics and ComputerIntegrated Manufacturing 37, 23 - 32.

[20] Lee, C. -M., Woo, W. -S., and Roh, Y. -H. 2017. Remanufacturing: Trends and Issues, International J. of Precision Eng. and Manuf. Green Tech. 4, 113 - 125.

[21] Tateno, T., Kondoh, S., 2017. Environmental Load Reduction by Customization for Reuse with Additive Manufacturing. Procedia CIRP 61, $241-244$.

[22] Holmström, J., Gutowski, T. 2017. Additive Manufacturing in Operations and Supply Chain Management: No sustainability benefit or virtuous knock-on opportunities?. J. of Industrial Ecology 21.

[23] Wits, W. W., García, J. R. R., and Becker, J. M. J. 2016. How additive manufacturing enables more sustainable end-user maintenance, repair and overhaul (MRO) strategies. Procedia CIRP 40, 693 - 698.

[24] Yesildag, N., Hopmann, C., Windeck, C., Bremen, S., Wissenbach K., and Merkt, S. 2017. Opportunities and Challenges of Profile Extrusion Dies Produced by Additive Manufacturing Processes. AIP Conference Proceedings 1914, 040002.

[25] Brøtan, V., Berg, O. A., and Sørby, K. 2016. Additive manufacturing for enhanced performance of molds. Procedia CIRP 54, 186 - 190

[26] Bours, J., Adzima, B., Gladwin, S., Cabral, J., and Mau, S. 2017. Addressing Hazardous Implications of Additive Manufacturing: Complementing Life Cycle Assessment with a Framework for Evaluating Direct Human Health and Environmental Impacts. J. of Industrial Ecology.

[27] Baumers, M., Duflou, J. R., Flanagan, W., Gutowski, T. G., Kellens, K., and Lifset, R. 2017. Charting the Environmental Dimensions of Additive Manufacturing and 3D Printing. J. of Industrial Ecology.

[28] Gobbo Junior, J. A., Busso, C. M., Gobbo, S. C. O., and Carreão, H. 2018. Making the links among environmental protection, process safety,and industry 4.0. Process Safety and Environmental Protection 117, $372-382$.

[29] Joshi, S. C., Sheikh, A. A. 2015. 3D printing in aerospace and its long-term sustainability. Virtual and Physical Prototyping, 10, $175-185$.

[30] Popov, V., Katz-Demyanetz, A., Garkun, A., Muller, G., Strokin, E., and Rosenson, H. 2018. Effect of Hot Isostatic Pressure treatment on the Electron-Beam Melted Ti-6Al-4V specimens. Procedia Manufacturing $21,125-132$.

[31] Michael P. Francis, Nathan Kemper, Yas MaghdouriWhite, Nick Thayer, 2018. "9 - Additive manufacturing for biofabricated medical device applications, Editor(s): Jing Zhang, Yeon-Gil Jung, Additive Manufacturing, Butterworth-Heinemann, $311-344, \quad$ ISBN 9780128121559 . 